\title{
PROJETO DE EXTENSÃO NA MODALIDADE EAD: "STARTUPS: FERRAMENTAS PARA O DESENVOLVIMENTO DE NEGÓCIOS INOVADORES COM O USO DE TECNOLOGIAS"
}

\author{
LONDRINA/PR JULHO/2018
}

\author{
Grace Botelho - Kroton - grace.botelho@kroton.com.br \\ Juliane Regina Bettin Santana - Kroton - juliane.santana@kroton.com.br \\ Marcio Ronald Sella - Kroton - marcio.sella@kroton.com.br \\ Fernando Alves Negrão - Kroton - fernando.alves@kroton.com.br \\ Dorival Magro Junior - kroton - dorival@kroton.com.br \\ Bruno Scaramuzza - Kroton - bruno@kroton.com.br
}

Tipo: Relato de Experiência Inovadora (EI)

Categoria: Métodos e Tecnologias

Setor Educacional: EDUCAÇÃO SUPERIOR

\begin{abstract}
RESUMO
A extensão universitária é uma forma de interação que deve existir entre a universidade e a comunidade na qual está inserida, sendo um dos objetivos da extensão, a disseminação do conhecimento pela universidade, essa trabalha questões relevantes no âmbito social e econômico. Esse artigo apresenta os dados do projeto de extensão que foi realizado nos meses de Abril e Maio de 2018 na modalidade a distância em uma Universidade Brasileira, o projeto de extensão teve carga horária de 20 horas e foi dividido em 5 encontros, onde cada um deles foi trabalhado um tema complementar ao tema central "Startups: ferramentas para o desenvolvimento de negócios inovadores com o uso de tecnologias". O evento foi ofertado no modelo blended learning sendo composto por dois momentos: o primeiro, composto por uma vídeo aula disponibilizada no Ambiente Virtual de Aprendizagem (AVA), contendo os conceitos teóricos de cada um dos temas elencados e o segundo momento contou com a participação de co-fundadores de startups e especialistas com ampla experiência no mercado, onde os temas foram discutidos em formato de Talk Show, com transmissão ao vivo por meio do sistema presencial conectado. Este momento proporcionou a interação dos convidados com os participantes inscritos, levantando questões para debates e reflexões importantes sobre as temáticas, os participantes encaminhavam suas perguntas via chat e eram respondidas ao vivo pelos convidados. O projeto de extensão teve 1881 participantes, sendo 1762 alunos da Instituição e 119 da comunidade externa, dividido em 144 cidades Brasileiras.
\end{abstract}

Palavras-chave: projeto de extensão, ensino a distância, startups 


\section{INTRODUÇÃO}

A extensão universitária é uma forma de interação que deve existir entre a universidade e a comunidade na qual está inserida. Santos (2010) enfatiza que a extensão, como atividade acadêmica, distingue-se das demais por constituir um processo metodológico que pergunta pela relevância social do ensino e que procura referências objetivas aos problemas reais que envolvem a sociedade. Frente a esse objetivo, é importante que a disseminação do conhecimento pela universidade, contemple questões relevantes no âmbito social e econômico.

\footnotetext{
Nesta vertente, destaca-se o empreendedorismo, um fenômeno socioeconômico global, que tem despertado interesse em governos, universidades, empresas e indivíduos (ABREU; CAMPOS, 2016). Magalhães (2016) destaca que a formação de novos sujeitos passa, necessariamente, pela formação empreendedora, pois o sujeito que se destaca neste novo tempo, é aquele capaz de fazer a diferença, convicto de que se não inovar, não terá destaque algum em um mercado cada vez mais competitivo.
}

O Sebrae e a Endeavor (2016) ressaltam que para gerar um melhor ambiente de negócios e desenvolver os ecossistemas empreendedores locais, é importante que as instituições de ensino superior sejam agentes-chave dessa transformação, em razão do seu potencial de impacto na comunidade ou seja, as universidades precisam explorar mais o seu potencial de inspirar e estimular a ambição e inovação nos empreendedores universitários. Além disso, precisa estar cada vez mais conectada com seus alunos, com o mercado e com a comunidade.

Assim, considerando a importância da extensão, no que se refere à integração da universidade com a comunidade e a abrangência do ensino à distância, foi pensado em um tema atual e inovador, cujos conhecimentos disseminados pudessem estimular o processo empreendedor e o surgimento de novas ideias, fomentando assim 0 desenvolvimento social e econômico nas mais diversas regiões do país.

Com vistas a esses objetivos, criou-se o Projeto de Extensão com o tema "Startups: ferramentas para o desenvolvimento de negócios inovadores com o uso de tecnologias", que buscou, por meio dos temas abordados, contribuir para a capacitação dos participantes em criar respostas aos desafios apresentados na atualidade.

\section{REFERENCIAL TEÓRICO}

\subsection{A importância da extensão como um dos pilares da Universidade}

A extensão universitária é o instrumento utilizado pela universidade para entregar o produto universitário, frutos do estudo e da pesquisa, para a comunidade. Deve ser 
articulado entre o estudo e a pesquisa para levar o conhecimento gerado dentro da instituição o mais próximo de aplicações úteis à sociedade, além de servir para a formação do cidadão de dentro e fora da comunidade acadêmica (KLEIN, KLEIN, BACK, 2004).

No Brasil, a prática de extensão universitária teve seu inicio nos anos 30 e tinha como dever retornar à população suas produções e conhecimentos, na maioria dos casos em via única, na qual o conhecimento fluía da universidade para a comunidade. A partir da década de 60 , o conceito de pesquisa, ensino e extensão começa a ser atrelado às universidades, assim as instituições de ensino superior (IES) passaram a incorporar políticas que contemplassem concepções e diretrizes para a extensão universitária (NEBEL, LANZETTA, GAIGER, 2011). A importância da extensão universitária foi inserida na Constituição brasileira de 1988, que destaca o ensino, a pesquisa e a extensão como práticas indissociáveis (MURENBERG et al, 2014).

Segundo CASTRO (2004), o que se nota a respeito dos projetos de extensão é que sempre apareceu como maneira de aproximar a universidade da população, principalmente de forma assistencial e ainda de caráter opcional. Porém a extensão se bem explorada, pode contribuir com uma mudança no processo de aprender e ensinar, pois possui arsenal metodológico diferenciado, é feita de encontros entre alunos, professores e a comunidade, no qual tem-se a possibilidade de incorporar diferentes conhecimentos e gerar reflexão sobre as práticas. Já NEBEL, LANZETTA e GAIGER (2004) afirmam que a extensão universitária passou a ser compreendida em uma posição tão importante quanto a pesquisa e o ensino. Afinal, é por conta da extensão universitária que os conhecimentos teóricos produzidos são confrontados com os dados empíricos imediatos, gerando permanente reelaboração das teorias e a construção do conhecimento científico, por isso a extensão não deve estar dissociada da pesquisa e do ensino.

A extensão universitária também contribui para o desenvolvimento da inclusão social, pois é responsável por articular diferentes atividades de ensino, adaptando-se às demandas da população. É um espaço fértil e propício para os alunos, enquanto graduandos, colocarem em prática os ensinamentos adquiridos em sala de aula, mostrarem atitudes, competências e habilidades, trazendo para a sua formação a realidade da comunidade (NOBRE et al, 2017).

Por isso, não só as escolas públicas de ensino superior, como também as IESs privadas têm realizado ativamente projetos de extensão, que causam mudança social e desenvolvimento local, atingindo mais de 18 milhões de pessoas, segundo a Associação 
Brasileira das Mantenedoras do Ensino Superior (ABMES) somente em 2004 (MURENBERG et al, 2014).

\subsection{Relevância do tema proposto no contexto atual}

Segundo a pesquisa GEM (2017) o empreendedorismo tem se mostrado uma ferramenta de desenvolvimento econômico e que traduz o desejo de muitos brasileiros. Atualmente, ter um negócio é o quarto sonho da nossa população, atrás de viajar pelo Brasil, comprar a casa própria ou um automóvel (GEM, 2017). A mesma pesquisa demonstrou que o Brasil aparece em primeiro lugar como o país em que há maior potencial de empreendedores, ou seja, mais de um quarto da população adulta (entre 18 e 64 anos) pretende empreender nos próximos três anos (GEM,2017).

Essa enorme capacidade de empreender e o número crescente de oportunidades deve ser conectada pela inovação, que é capaz de transformar realidades, expandindo nossa percepção sobre o mundo que nos rodeia (ABREU; CAMPOS, 2016). Neste contexto, destacam-se as startups, modalidade de empreendimento que tem um papel importante no aprimoramento e desenvolvimento de ideias inovadoras e novas tecnologias. Thurner (2015) destaca que as startups trabalham com diversos tipos de inovação como: reposicionamento de tecnologias para novos usos, inventando novos modelos de negócios que revelem valores até então desconhecidos, ou simplesmente levando um produto ou serviço para novas localidades ou para um público carente do que é ofertado.

A Associação Brasileira de Startups (ABStartups, 2018) evidencia que as startups são importantes pois representam o futuro, sempre dando um passo a mais na curva de aprendizado e mostrando caminhos para problemas novos e antigos. Lima (2016) aponta que a importância das startups é que as mesmas possuem diversas características que possibilitam a obtenção de ganhos escaláveis em intervalos de tempo considerados pequenos, quando comparados à indústria e à outros tipos de negócios tradicionais Isto, segundo o autor são características específicas que permitem que este tipo de empresa seja capaz de ocasionar desenvolvimento econômico veloz e a geração de empregos com elevados salários, causando impactos positivos sob a perspectiva econômica e social.

Assim, considerando os impactos da tecnologia em modelos tradicionais de negócios e os efeitos positivos das startups no desenvolvimento da economia, mostrou-se relevante a abordagem do tema no contexto acadêmico por meio da oferta do Projeto de Extensão. Atividades diversas de educação empreendedora são essenciais para 
desenvolver competências no aluno, permitir o ensino prático (que muitas vezes não são possíveis em sala de aula) e integrá-lo com outros alunos, de diferentes cursos, incentivando a interdisciplinaridade (SEBRAE; ENDEAVOR, 2016). A explosão de ideias, a vontade de resolver um problema, a incrível sensação de se desenvolver um produto, um conceito, que resolva uma determinada "dor" são inerentes aos empreendedores que se lançam no mundo dos negócios através das startups, na maioria das vezes, pela primeira vez.

Muitos desses se deparam, depois de uma pesquisa mais aprofundada, com outros empreendedores que estão desenvolvendo soluções parecidas e que, provavelmente, irão apresenta-las ao mesmo tempo ao mercado em busca de investidores. A intenção deste projeto é justamente apresentar à comunidade interessada, tecnologias que possam ser o diferencial na ideia do empreendedor ou ainda despertar novas ideias, utilizando as tecnologias debatidas.

\section{PROCEDIMENTOS METODOLÓGICOS}

O projeto de extensão teve como tema central "Startups: ferramentas para o desenvolvimento de negócios inovadores com o uso de tecnologias" com carga horária de 20 horas e foi ofertado no modelo blended learning sendo composto por dois momentos: o primeiro, composto por uma vídeo aula disponibilizada no Ambiente Virtual de Aprendizagem (AVA), contendo os conceitos teóricos de cada um dos temas elencados; e, o segundo, contou com a participação de co-fundadores de startups e especialistas com ampla experiência no mercado, onde os temas foram discutidos em formato de Talk Show, com transmissão ao vivo por meio do sistema presencial conectado. $\mathrm{O}$ momento presencial proporcionou a interação dos convidados com os participantes inscritos, levantando questões para debates e reflexões importantes sobre as temáticas. No total, foram abordados 5 temas:

- Tema 01: Entendendo o conceito de Startup e o processo de validação da ideia

- Tema 02: Estratégias de Marketing e Marketing Digital para Startups

- Tema 03: Web sites, e-business e e-commerce.

- Tema 04: Realidade Virtual (VR), realidade aumentada, internet das coisas e segurança.

- Tema 05: Tecnologia RFID (Radio Frequency IDentification) e as Lojas inteligentes. 
Os temas propostos foram amplamente trabalhados em busca de aderência às principais tendências de negócios para as Startups. Nesse sentido, é fato que o emprego da tecnologia ganha destaque e é o diferencial para os negócios.

Em se tratando de tecnologias para as Startups, podemos sinalizar que foram abordadas no evento algumas soluções conforme a seguir:

* Cidades e Lojas Inteligentes: Soluções que mostram como interação e conectividade podem ajudar no dia a dia urbano, por meio de ações inovadoras, como serviços colaborativos, estacionamentos inteligentes e armazenamento de objetos.

* Realidade virtual: oferecer inovações para diversos setores, como engenharia, arquitetura e games.

* Internet das coisas: Apresentação das ferramentas que agregam a internet ao dia a dia dos consumidores.

* Inteligência artificial: A capacidade de máquinas pensarem como humanos.

* Serviços em nuvem: Soluções para as empresas que trabalham com e-commerce ou grandes acúmulos de dados, ou seja, empresas inovadoras têm trabalhado para baratear o custo dessas operações com os serviços de armazenamento em nuvem.

O projeto foi amplamente divulgado aos polos, comunidade externa e alunos da universidade, sendo que o convite para participação do curso se estendeu a todos os cursos do portfólio da IES: tecnólogos, bacharelados e licenciaturas. No que se refere à aderência do conteúdo ofertado para convalidação de carga horária de atividades complementares, 31 cursos, afirmaram que o conteúdo era aderente ao curso.

\section{DADOS DO EVENTO}

O projeto de extensão teve uma aderência alta dos polos de apoio presencial, sendo que 175 polos apresentaram interesse em ofertar o projeto. $O$ interesse por parte dos alunos e comunidade externa também foi satisfatório, houve um total de 1881 participantes, divididos em 23 estados brasileiros e 144 cidades brasileiras. O Gráfico 01, apresenta a quantidade de participantes por Estado.

\section{Gráfico 01: Participantes do Projeto de Extensão por Estado}




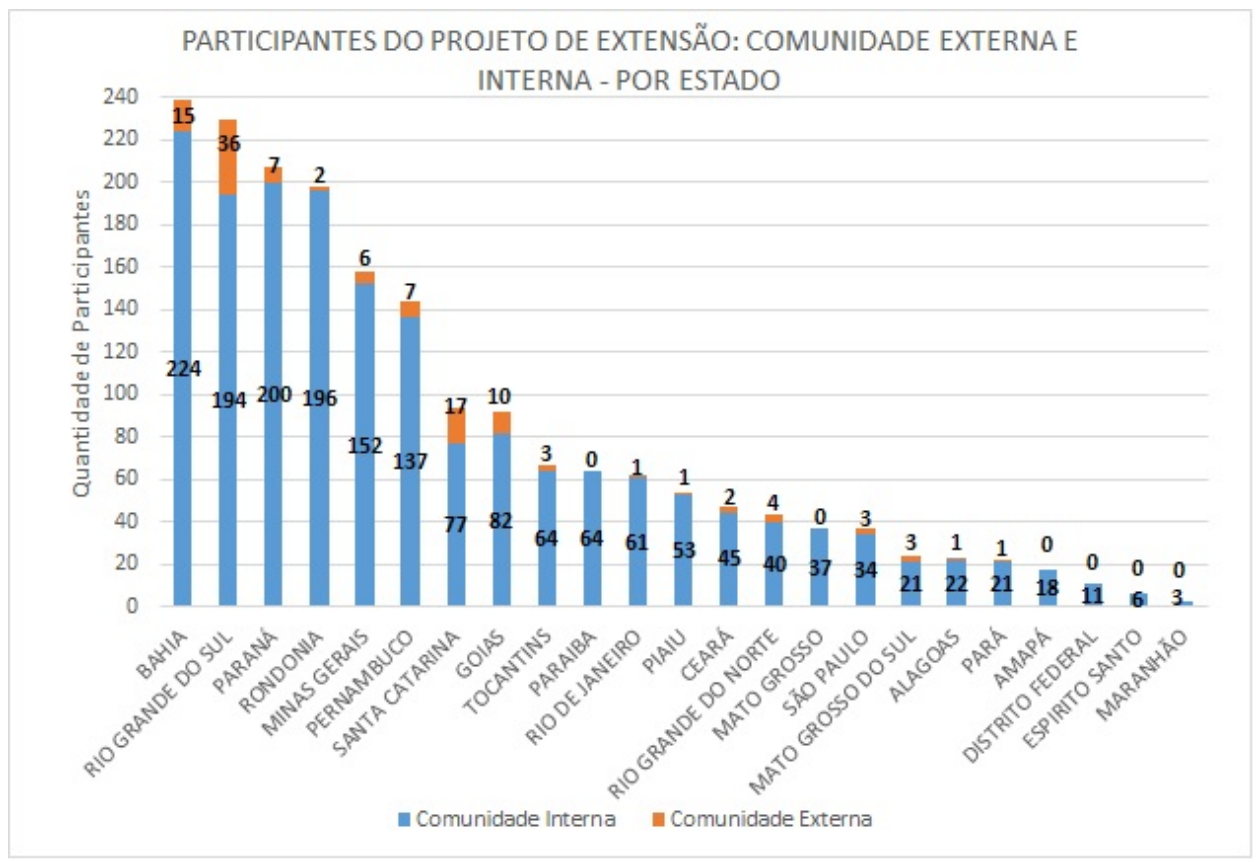

Fonte: Elaborado pelos autores, 2018.

Em análise ao Gráfico 01 observa-se que os cinco Estados que tiveram maior número de participantes foram: Bahia (12,7\%), Rio Grande do Sul (12,2\%), Paraná (11\%), Rondônia (10,5\%) e Minas Gerais (8,4\%), sendo estes os Estados que tiveram o maior número de cidades com oferta do Projeto de Extensão. No que diz respeito aos participantes por região, verifica-se que a região Nordeste teve o maior número de participantes, o equivalente a $33 \%$, seguido pelas regiões Sul $(28 \%)$, Norte (16\%), Sudeste (14\%) e Centro-Oeste (9\%).

Também é importante destacar a participação da comunidade externa no evento, sendo que, em relação à participação da comunidade interna identifica-se um percentual bem menor. Ou seja, 94\% dos participantes foram da comunidade interna e $6 \%$ da comunidade externa. Tal disparidade pode ser explicada pela facilidade de divulgação através das ferramentas de Tecnologias de Informação e Comunicação (TIC) na comunidade interna, com destaque para a ampla divulgação realizada pela tutoria ativa e divulgação no início das tele aulas. Já tal facilidade de divulgação não ocorre com a comunidade externa, a qual depende das ações dos polos de apoio presencial, ou mesmo via convite da comunidade interna, para tomar conhecimento do evento. Ainda assim, pode-se citar que 119 participantes sem vínculo com a IES foram impactados pelo evento, com destaque para a região sul, a qual representa 60 participantes ou aproximadamente $51 \%$ de toda a comunidade externa. Neste sentido, ressalta-se a participação da comunidade externa nos Estados de Santa Catarina, Rio Grande do Sul e Mato Grosso do Sul, os quais tiveram os maiores percentuais de participação, sendo $18 \%, 16 \%$ e $13 \%$, respectivamente. 


\section{DISCUSSÃO DOS RESULTADOS}

O projeto de extensão "Startups: ferramentas para o desenvolvimento de negócios inovadores com o uso de tecnologias" foi realizado em 5 encontros, com a participação de um total de 1881 participantes entre comunidade interna e externa, tendo um alcance de 22 estados brasileiros, o que mostra o grande alcance e potencial dos projetos de extensão na modalidade a distância. Além dos números de inscritos do projeto, vale ressaltar a quantidade e qualidade da participação da comunidade durante os dias de transmissão ao vivo do evento, os quais interagiram efetivamente com os convidados por meio do chat mediado por um tutor. Os participantes encaminharam uma grande quantidade de perguntas, elevando o nível do debate durante o Talk Show.

Projetos de extensão por definição devem entregar à comunidade o produto do ensino e da pesquisa desenvolvidos dentro da IES, assim como também são uma ferramenta de troca de conhecimento, em via de duas mãos, entre a comunidade e a universidade. Dessa forma o projeto proposto consegue entregar o que se espera de projetos de extensão, pois a comunidade trouxe seu conhecimento através da participação dos convidados, assim como contribuiu com as dúvidas e comentários. Assim, a IES cumpre seu papel promovendo o desenvolvimento social, levando o conhecimento prático e acadêmico aos participantes, de forma que os futuros empreendedores possam se lançar no universo das Startups com mais conhecimento a respeito das tecnologias, reduzindo o risco do investimento e criando negócios de melhor qualidade que impactem e gerem empregos nas mais diversas regiões do Brasil.

É importante também ressaltar a participação da comunidade externa nesse evento, pois mesmo em proporção menor em relação à comunidade interna, $6 \%$ do total de participantes representa um número significativo de pessoas. Esse número chama a atenção em relação ao potencial de crescimento da participação da comunidade externa nos próximos eventos, pois além do impacto social gerado pelo projeto, também pode ser utilizada pelos polos de apoio presencial como forma de se aproximar da comunidade local, estabelecer uma relação e legitimar a IES junto a sociedade a qual o polo está inserida. Em um âmbito econômico, também pode ser gerador de receita além de oportunidade de captação e retenção de alunos.

\section{CONCLUSÕES}

Pode-se afirmar que a grande motivação para a oferta de um projeto de extensão de tamanha expressividade, envolvendo vários cursos do Ensino à Distância foi a responsabilidade social para com as comunidades, que cada vez mais são obrigadas a 
assumir riscos, buscar alternativas de trabalho e renda, principalmente devido ao momento de crise instalado no país. Assim, é papel das Universidades, levar temas de relevância aos seus alunos e à comunidade na qual está inserida, fomentando o espírito empreendedor e o surgimento de novas ideias e novas soluções para os problemas enfrentados pela sociedade, estimulando a criação de novos negócios, geração de empregos e renda e favorecendo o desenvolvimento econômico. Nesse contexto, é importante destacar a abrangência e o alcance do Ensino à Distância, e sua capacidade de levar o conhecimento de qualidade, de forma igualitária, à diversas regiões do Brasil. Dessa forma, é possível dizer que este projeto de extensão, além de contribuir para a capacitação de diversas pessoas, teve como papel, constituir um fragmento desta grande construção que é a educação. Com isso é necessário que cada vez mais as Universidades, Centros Universitários e Faculdades tenham a iniciativa de abrir as suas portas para debater temas de relevância que fomentem o ecossistema empreendedor, por meio de oferta de extensão, o que foi alcançado pelo projeto de extensão Startups: ferramentas para o desenvolvimento de negócios inovadores com o uso de tecnologias.

\section{REFERÊNCIAS BIBLIOGRÁFICAS}

ABREU, Paulo R. M.; CAMPOS, Newton M. O panorama das aceleradoras de Startups no Brasil. USA: CreateSpace Independent Publishing Plataform, 2016.

ABSTARTUPS - Associação Brasileira de Startups. Sobre a ABSTARTUPS. Disponível em . Acesso em: 07 de maio de 2018.

CASTRO, Luciana M. Cerqueira. A Universidade, a Extensão Universitária e a Produção de Conhecimentos Emancipadores. In: 27를 Reunião Anual Da Anped Sociedade, Democracia E Educação: Qual Universidade?, 2004, Caxambu. Http://Www2.Uerj.Br/Anped11, 2004.

GEM - GLOBAL ENTREPRENEURSHIP MONITOR. Coord. Maria de Souza Silveira Greco Empreendedorismo no Brasil 2016. Curitiba: IBQP, 2017.

KLEIN, SHEILA ELISA SCHEIDEMANTEL ; KLEIN, RALF ; BACK, CARLA C. . A Importância Da Extensão Na Graduação: O Programa Furb Visita Sua Rua. In: Cobenge 2004 - Congresso Brasileiro De Ensino De Engenharia, 2004, Brasília. Cobenge 2004, 2004.

LIMA, João Cardim Ferreira. Inovação Radical: o panorama das Startups brasileiras, uma análise através da modelagem de equações estruturais. Dissertação de Mestrado. 
Universidade Federal do Rio Grande do Norte, 2016.

MAUERBERG JR, A. ; GeRREIRO, J. ; COStA, C. C. M. ; FERREIRA, M. A. M. .A Universidade Enquanto Espaço Territorial De Inovação: $O$ Papel Da Extensão Universitária No Incentivo Às Práticas Inovadoras De Gestão. Organizações Rurais E Agroindustriais (Ufla) , V. 16, P. 220-232, 2014

NEBEL, GITANA. C. S. ; LANZETTA, S. ; GAIGER, P. .A Inclusão Da Extensão Universitária Na Formação Curricular: A Proposta Do Núcleo Rondon Da Universidade Federal De Pelotas.. In: Xi Congreso Iberoamericano De Extension Universitaria, 2011, Santa Fé, Argentina. XI Congreso Iberoamericano De Extensión Universitaria :Integración, Extensión, Docencia E Investigación Para La Inclusión Y Cohesión Social.. Santa Fé, Argentina.:Edicionesunl, 2011. P. 1-12.

NOBRE, R.S. ; MOURA, J.R.A. ; BRITO, G.R. ; GUIMARÃES, M.R ; SILVA, ANA Roberta Vilarouca Da . Vivenciando A Extensão Universitária Através De Ações De Educação Em Saúde No Contexto Escolar. Revista De Aps (Online), V. 20, P. 288-292, 2017.

THURNER, Bruno da Veiga. Empreendedorismo e Inovação: a influência das Startups no crescimento econômico. Dissertação de Mestrado. Universidade Federal de Santa Maria-RS, 2015.

SEBRAE; ENDEAVOR BRASIL. Empreendedorismo nas Universidades brasileiras. 2016. Disponível em: . Acesso em 07 de maio de 2018.

SILVA, L. D. A Gestão Da Extensão Universitária: Uma Nova Sinergia Entre Os Três Pilares Da Educação Superior Universitária. In: Encontro Nacional De Ensino E Pesquisa Em Administracao, 4., 2013, Brasília.Anais... Brasilia: Enepq, 2013. P. 1-16. 